\title{
RICOEUR E GADAMER: A COMPREENSÃO DO OUTRO COMO PERSPECTIVA ÉTICA DA HERMENÊUTICA
}

\author{
José Wilson Rodrigues de Brito \\ Mestrando em Filosofia pela Universidade Federal do Piauí \\ nosliwbrito@hotmail.com \\ Helder Buenos Aires de Carvalho \\ Doutor em Filosofia pela Universidade Federal de Minas Gerais; Professor da UFPI \\ buenos36@hotmail.com
}

\begin{abstract}
Resumo: O presente artigo trata, a partir de Ricoeur e Gadamer da dimensão do outro como uma perspectiva ética da hermenêutica. Para isto, se recorre como bibliografia primária às obras $O \mathrm{si}$ mesmo como outro, de Paul Ricoeur e La Herencia de Europa, de Gadamer. Além destas obras também são citadas mais obras de outros autores que auxiliam na fundamentação deste trabalho. $O$ desenvolvimento textual percorre uma subdivisão em quatro partes: a) Do problema do eu à dimensão do outro na visão ética de Ricoeur; b) O diálogo como visada ética do outro em Paul Ricoeur; c) O diálogo solidário como abertura à compreensão do outro; d) O projeto hermenêutico de Gadamer numa perspectiva cosmopolita frente ao pluralismo cultural. Considera-se, então, que ambos os autores aqui trabalhados têm a preocupação de com a dimensão do outro frente às alteridades que lhes são postas, de modo que a compreensão e o diálogo solidário são alternativas pertinentes aos conflitos de ideias e culturas diferentes na contemporaneidade.
\end{abstract}

Palavras-Chave: Compreensão. Ética. Gadamer. Hermenêutica. Outro. Ricoeur.

\section{RICOEUR AND GADAMER: THE UNDERSTANDING OF THE OTHERS AS AN ETHICAL PERSPECTIVE OF THE HERMENEUTICS}

Abstract: The present paper deals with, from Ricoeur's and Gadamer perspective, the dimension of the other within an ethical perspective of hermeneutics. For this end, we use as a primary bibliography the works Oneself as Another, by Paul Ricoeur and The Heritage of Europe, by Gadamer. In addition to these works we also cite more works by other authors that help in the substantiation of this work. The textual development goes through a subdivision into four parts: a) From the problem of the self to the dimension of the other in the ethical view of Ricoeur; b) Dialogue as ethical aim of the other in Paul Ricoeur; c) Solidary dialogue as an openess to understand the other; d) Gadamer's hermeneutic project in a cosmo-political perspective in the face of cultural pluralism. It is then considered that both authors here are concerned with the dimension of the other in the face of the alterities that are put to them, so that understanding and solidary dialogue are alternatives pertinent to the conflicts of ideas and different cultures in the contemporary world.

Keywords: Understanding. Ethic. Gadamer. Hermeneutics. Other. Ricoeur. 


\section{Considerações Iniciais}

Este trabalho tem como tema 'Ricoeur e Gadamer: a compreensão do outro como perspectiva ética da hermenêutica', no qual há uma reflexão sobre o problema concernente à dimensão ética e política na hermenêutica contemporânea. Isto por que tem se tornado cada vez mais instigante este tipo de pesquisa destas duas áreas de conhecimento da Filosofia. Como bibliografia principal, foram adotadas as obras O si mesmo como outro, de Paul Ricoeur e La Herencia de Europa, de Gadamer. Além destas obras também se recorre a demais textos dos autores mencionados acima, bem como de outros para que haja uma maior profundidade quanto ao tratar desta temática.

Ao longo deste trabalho se pretende mostrar, nas teorias hermenêuticas de Ricoeur e de Gadamer, uma relação no que tange à questão da discussão sobre a noção de outro e a tentativa de ampliarem este debate ao campo da práxis filosófica, culminando com a visão de aspectos comuns, como por exemplo, a vivência de valores cultivados por grupos diversos, onde deve prevalecer a dimensão do diálogo solidário como forma de abertura à resolução dos problemas de conflitos relacionados a ideias e culturas diferentes.

\section{Do Problema do Eu à Dimensão do Outro na Visada Ética de Ricoeur}

A reflexão a respeito da questão do outro na filosofia não teve a mesma importância que "a pergunta pelas causas do mundo, pela alma, pela justiça e tampouco é uma tematização específica da tradição do pensamento filosófico até o medievo" (HERMANN, 2011, p. 138). Isto por que esta questão teve seu início de abordagem principalmente no pensamento moderno, uma vez que ali se acentua 0 princípio da subjetividade, bem como da forma como o sujeito se relaciona com o outro. Torna-se necessário destacar que o termo "outro" geralmente acaba sendo associado ao que seja tomado como estranho, ou que lhe seja contrário à identidade, visto, então, como distinto e inverso.

Neste sentido, é possível afirmar que a filosofia do sujeito é vista como algo paradigmática, pois numa visão cartesiana, que é severamente criticada por Ricoeur, o ego cogito, ou seja, o eu penso dá novos rumos à filosofia no que se refere a todas as relações. Com isto, este eu mencionado por Descartes teria sua expressão sem uma real confrontação com o que esteja fora de si mesmo, de modo que se tornaria uma espécie de eu apenas em si, ao ponto de parecer sem abertura ao que lhe seja exterior.Daí, surge algumas problemáticas relacionadas a este eu enquanto sujeito na teoria moderna, tendo em vista que, entre os gregos não existia, de modo centralizado, esta preocupação com a questão da subjetividade, pois "a preocupação maior era a Polis aglutinadora da vida eminentemente humana e na qual a liberdade era desfrutada no convívio entre os iguais" (LEONHARDT, 2004, p. 46).

É possível observar, a partir desta menção ao eu sujeito da filosofia de Descartes, que em sua reflexão se tem como essencial a questão da razão, de maneira que é de elevada importância sua contribuição inicial para esta problemática no contexto filosófico da modernidade. Isto por que havia ainda grandes déficits no que se refere ao problema do sujeito cognoscente, uma vez que 
não era possível, para Descartes, alcançar a verdade com as bases especulativas de seu tempo. Daí tê-las considerado como incompletas frente à condução do conhecimento verdadeiro, precisando, então, estabelecer um novo método que pudesse oferecer um fundamento metódico que não mais ocasionasse dúvida quanto às formas de conhecer a realidade que nos circunda.

Descartes propõe a dúvida metódica como maneira de alcançar a base primeira da qual não se possa em nenhum momento duvidar, para então, poder avançar às etapas posteriores de como chegar ao conhecimento verdadeiro. Assim, esta dúvida pode ser tomada como este constante desejo de ter certeza do conhecimento, que para ele é o fundamento do cogito, que como bem afirmaScruton: "Consoante Descartes esta proposição [eu penso] é peculiar na medida em que não pode ser cogitada sem, ao mesmo tempo e pela mesma razão, ser verdadeira" (SCRUTON, 1982, p. 37). Assim, o eu penso já pode ser tomado como uma verdade, pois apenas pelo fato de ser pensada, a mesma já é posta como verdade em si assegurada. Há ainda em sua formulação do ego cogito uma ressalva a ser feita, que é a de considerar uma única referência a ser subentendida, o eu pensante, que "logo após percebi que, quando pensava que tudo era falso, necessário se tornava que eu - eu que pensava era alguma cousa (sic)" (DESCARTES, 1960, p. 89).

Com isto, Descartes defende em sua teoria certa prioridade do eu que se volta especificamente para si mesmo, ou seja, apenas para o conteúdo da consciência. Como bem afirma este pensador: "por isso reconheci que eu era uma substância cuja essência ou natureza não é outra cousa (sic) senão pensamento que, para existir, não tem necessidade de nenhum lugar nem depende de cousa alguma material" (DESCARTES, 1960, p. 91).

Com isto, pode ser afirmado que o eu, enquanto não dependente de qualquer tipo de alteridade pode ser visto como uma forma de condição tomada como précognitiva a priori, pois abaixo da mesma o outro se torna disponibilizado. Assim, proporcionando uma maior amplitude de significados associados em conexão uns com os outros. Deste modo, se interconectam em suas diversidades conceituais, como por exemplo, o outro e o estranho, o eu e a alteridade.

$\mathrm{O}$ eu, neste sentido, teria toda autoridade para afirmar algo como verdadeiro ou não, tendo em vista que o que estiver na mente é tomado como o mesmo que aparece ao eu. Assim podem ser levantadas algumas questões concernentes ao paradigma moderno do eu como sujeito, como consciência, a saber, as seguintes: "como ter acesso ao outro? Ele é apenas uma representação? O outro é aquilo que é estranho ao eu? Eles são excludentes ou complementares?" (HERMANN, 2011, p. 138). Daí, então, podemos denotar a tentativa de uma visada ética para a questão do outro na filosofia de Paul Ricoeur, observando, claro, as colaborações de Descartes em ter aberto a discussão sobre a questão da consciência, do eu sujeito, de modo que, positivamente, ocogito cartesiano se posiciona na modernidade como filosofia relacionada especificamente ao sujeito, embora com sua dimensão hiperbólica no que tange à dúvida metódica acarrete, consequentemente, seu distanciar-se de qualquer que seja a relação com a pessoa da qual a investigação de âmbito filosófica tenha como seu sentido último.

É notório que mesmo com sua conquista de estabelecer um novo paradigma dentro das discussões filosóficas rumo à certeza indubitável pelo método da dúvida, Descartes, ao exaltar por demais o cogito, na visão de Ricoeur, sucumbiu à 
atomização do sujeito, ou seja, não o contextualiza a partir de um reconhecimento de identidade pertencente e uma determinada história, pois "essa ambição é responsável pela enorme oscilação sob cujo efeito o 'eu' do 'eu penso' parece ora exaltado excessivamente à categoria de primeira verdade, ora rebaixado à categoria de grande ilusão" (RICOEUR, 2014, p. 23).Assim, Ricoeur defende que o cogito não deve ser tomado especificamente como a verdade primeira, mas sim, como uma das verdades possíveis do sujeito, tendo em vista que, como afirma o hermeneuta francês:

A problemática do si resulta, em certo sentido, amplificada, mas à custa da perda de sua relação com a pessoa de que se fala, com o eu-tu da interlocução, com a identidade de uma pessoa histórica, com o si da responsabilidade. A exaltação do cogito deve ter esse preço? A modernidade deve a Descartes pelo menos o fato de ter sido posta diante de uma alternativa tão temível (RICOEUR, 2014, p. 24).

Mesmo tecendo severas críticas à exaltação do cogito por parte de Descartes, Ricoeur reconhece que o mesmo fez uma tarefa de maior relevância para o pensamento filosófico da modernidade, de tal maneira que até os dias de hoje causa muita inquietação nos pensadores que se debruçam sobre suas teorias, a questão da consciência, a racionalidade posta como novo paradigma. É neste contexto da dimensão da identidade histórica de uma pessoa nesta relação entre eu-tu da interlocução que nosso hermeneuta coloca a questão ética da responsabilidade deste outro em suas relações, pois "uma hermenêutica da identidade narrativa para a qual a interpretação culmina na apropriação de si não pode deixar de comportar consequências éticas. Ela leva Ricoeur a abordar de frente a questão da ética, que sempre esteve no horizonte de sua obra" (GRONDIN, 2015, p. 101).

\section{O Diálogo como Dimensão Ética do Outro em Paul Ricoeur}

Dentro desta tentativa de compreensão da dimensão do outro e suas relações em referência ao que deve ser considerado ético, cabe destacar que o termo outro, tratado dentro do espectro de reflexão filosófica, fazia menção às questões éticas, isto através de discussões teóricas encontradas na própria filosofia antiga. Isto pode ser visto especialmente na filosofia de Platão, de modo que "o estranho ou o outro se situa no corpo e no afastamento penoso das pulsões e dos afetos. Nessa concepção de natureza humana, o corpo é o outro da alma e tende a se tornar estranho à própria identidade de si" (HERMANN, 2011, p. 139).

Desta maneira, é possível percebermos que na teoria de Platão a alma pode ser concebida como um princípio de vida que é incessante, pois "é mais afim que o corpo ao invisível e este ao visível” (PLATÃO, 1986, v. 3, p.70). Tem-se, então, que para Platão, há esta dicotomia entre alma e corpo, notando que a alma é vista como aquela parte do ser humano que consegue, por natureza, ser racional e deliberar, mantendo a identidade consigo mesma. Já no que tange às características do corpo - o estranho da alma - é aquela área humana que está capacitada a percebera multiplicidade, bem como a pluralidade da realidade. Assim, Ricoeur faz uma certa distinção entre a ipseidade e a mesmidade, alegando que: 
$\mathrm{Na}$ História narrada há, porém, elementos dissociativos representados pela diversidade dos acontecimentos, os componentes dessemelhantes das causas das intenções, dos casos que introduzem a dialética entre e mesmidade e a ipseidade. $\mathrm{Na}$ verdade é a pessoa que é a personagem narrativa. Suas vivências é que são narradas. A pessoa e suas experiências vividas são unidade (LEONHARDT, 2004, p. 52).

Por isto se pode afirmar que em Ricoeur há bastante espaço aberto para discussão a respeito da problemática da identidade na diferença, tendo em vista a ampliação de sua hermenêutica filosófica para a reflexão do campo ético. Cabe notar, então, que "o que é atestado, em último caso, é a ipseidade, ao mesmo tempo em sua diferença com respeito à mesmidade e na sua relação com a alteridade" (RICOEUR, 2014, p. 353).

Para Ricoeur, então, o si mesmo pode ser entendido especificamente como outro, de maneira que é a própria constituição de si, tendo em vista a vida em função do outro. Portanto, entre ipseidade e alteridade é verificada a existência de uma relação ontológica e dialética, pois como argumenta Ricoeur:

Que o outro seja desde o começo o pressuposto, o epoché pelo qual a análise se inicia, a prova uma primeira vez: de uma maneira ou de outra, eu sempre soube que o outro não é um dos meus objetivos de pensamentos; que ele me percebe a mim mesmo como um diverso dele mesmo; que, juntos, nós visamos o mundo como uma natureza comum; que juntos ainda, edificamos as comunidades de pessoas suscetíveis de se comportarem por sua vez sobre a cena da história como personalidades de grau superior (RICOEUR, 2014, p. 387).

Em Paul Ricoeur, a concepção de outro é necessária para que haja um melhor entendimento a respeito da ipseidade, tendo em vista que ela faz com que se tenha uma compreensão de conjunto da realidade. Assim, pode-se dizer que "a alteridade do outro decorre da identidade ipse e surge do entendimento que não pode ser dito eu sem que haja um tu. Do encontro fica evidenciada a ética da vivência em comum que se concretiza na solicitude e que, segundo Ricoeur, não é acréscimo, é abertura para a continuação do diálogo (LEONHARDT, 2004, p. 53). Fica claro, então, que em Ricoeur, o eu reconhece o outro, pois há o duplo sentido da alteridade, tendo em vista que a pessoa encontra no outro o próximo, nesta experiência do outro em si mesma, numa relação eu-tu pela abertura ao diálogo contínuo. Desta maneira, como conclui Leonhardt:

O reconhecimento do outro, sua posição seja como o diverso de si, o mesmo considerado outro seja o Outro que se coloca frente ao eu e que percebe alguém diferente de si mesmo é um desenho que vai aos poucos sendo esboçado até atingir a configuração de um ser postado diante de um sujeito humano frente a outro sujeito humano. Portanto, o eu reconhece o outro que insiste em se revelar no duplo sentido da alteridade (LEONHARDT, 2004, p. 56). 


\section{O Diálogo Solidário enquanto Abertura à Compreensão do Outro em Gadamer}

O presente estudo tenciona uma reflexão, a partir das obras Verdade $e$ Método (1960) e La Herencia de Europa (1990), ambas do filósofo alemão HansGeorg Gadamer, a respeito da temática relacionada à Comunidade política como espaço de abertura ao multiculturalismo.

A partir da elaboração teórica da hermenêutica de Gadamer pode ser notado, de modo mais preciso em seu ensaio Ciudadanos de dos Mundos, que o comum é tomado a partir de duas concepções de sentido. A saber, o primeiro é vislumbrado como a experiência que seja comum a todos, sendo, então, ocasionado pela linguagem; o segundo sentido para o comum, e que compete especialmente à nossa investigação, é tomado como resultado de práticas solidárias entre os indivíduos humanos, de maneira que se direciona pela necessidade de uma solidariedade comunicativa, ao ponto em que esta desemboca em uma função, de "aprender a reconhecer o comum nos outros"(GADAMER, 1990, p. 116).

O comum que nos vincula a todos não está dado, fechado ou mesmo fixo, mas em um constante fazer-se. Deste modo, pode-se afirmar que na atualidade há um novo imperativo moral, caracterizado especificamente por ativar e propiciar o diálogo entre as culturas. Isto é alcançado pela hermenêutica, uma vez que ela proporciona o entendimento do outro com o qual se convive.

Em Gadamer é possível notar este diálogo entre culturas como aquilo que pertence à melhor herança que pode ser dada pela Europa. Daí a importância de possibilitar uma forma de comunicação linguística que consiga superar o risco de ocorrer uma nova "Torre de Babel" (GADAMER, 1998, p. 111-113), metáfora esta que é bastante usada por Gadamer ao longo de seus escritos.

Cabe notar que o mundo de cada pessoa envolvida no diálogo "é configurado a partir de uma língua determinada concretamente em uma cultura" (GADAMER, 1983, p. 09). Assim, é possível perceber que em Gadamer a solução hermenêutica para a questão de um acordo para início de uma conversação perpassa os conceitos de alteridade do passado e abertura para a alteridade. Gadamer demonstra, então, que existe, a partir da consciência histórica a consciência das diferenças, de modo que, a partir desta compreensão, tem em aberto o caminho para a "superação na prática a povos e culturas estranhos" (GADAMER, 2002, p. 145).

O pensador Gadamer sustenta uma severa crítica ao sistema hegeliano de fundamentação teórica à questão da abstração, como meio de explicação de toda a realidade no mundo, menosprezando o papel do sujeito. Com esta centelha se nota claramente a importância da elaboração do projeto hermenêutico de Gadamer na construção de uma filosofia prática, onde esta visa "alcançar a continuidade da autoevidência, que somente a existência humana pode sustentar" (GADAMER, 2008, p. 166), e não lidar simplesmente com aspectos abstratos como propunha a filosofia hegeliana para motivar as discussões sobre os fenômenos na realidade existente.

Gadamer faz a seguinte questão, no que concerne à busca da vivência fatídica dos compromissos na comunidade: "O que é a filosofia prática? Como podem a teoria e a reflexão dirigir-se para o âmbito da práxis, visto que esta não tolera nenhum distanciamento, mas pelo contrário, exige o engajamento" (GADAMER, 2002, p. 32).

Em sua obra Verdade e Método II: Complementos e índices, na parte intitulada Sobre o problema da fenomenologia do espírito de Hegel, Gadamer 
explicita uma nova forma de compreender a realidade histórica ${ }^{1}$. A questão da alteridade se mostra de forma central nesta maneira de interpretar os fenômenos. Como pensado por Gadamer (2002), "ali está o outro que rompe com a centralidade do meu eu à medida em que me dá a entender algo" (GADAMER, 2002, p. 17).

A partir disso, é possível notar que Gadamer dá uma maior importância ao diálogo como "fundamentação de nossa orientação no mundo pelo elemento da linguagem" (GADAMER, 2002, p.17). Também cabe destacar que ao tratar da questão da consciência histórica, Gadamer argumenta que a mesma "é um problema sumamente dialético"(GADAMER, 2002, p.71), dando a entender que só é possível haver uma real compreensão recíproca pelo "entender-se sobre algo" (GADAMER, 2002, p.70), ou seja, partindo da "fusão do horizonte do presente com o horizonte do passado"(GADAMER, 2002, p. 70), que para Gadamer é entendido como consciência histórico-efeitual, ou seja, vivemos a cada momento na possibilidade de compreender-nos uns aos outros à medida em que nos abrimos ao que nos chega e se transmite, de modo que "o diálogo com os outros, suas objeções ou sua aprovação, sua compreensão ou seus mal-entendidos representam uma espécie de expansão de nossa individualidade e um experimento da possível comunidade a que nos convida a razão" (GADAMER, 2002, p. 246).

Daí a necessidade de uma hermenêutica como filosofia prática que nos propõe uma identidade, uma vez que na contemporaneidade se torna um risco à mesma a homogeneização da cidadania. Neste sentido, interpretação e crítica ao longo do próprio horizonte tornam possível o autoreconhecimento sem exclusão das diferenças, sendo, então, possível uma consciência de cidadania que seja aberta à alteridade.

Portanto, para Gadamer, ser cidadãos de dois mundos refere-se ao estar abertos ao outro pela pertença a um mundo cultural. Abertura esta associada ao conceito de aplicação, bem como ao de diálogo e fusão de horizontes, que podem proporcionar uma reconstrução do outro que seja respeitado em sua diferença. Desta maneira, Gadamer almeja com sua filosofia prática contribuir para que a comunidade política possa ser este espaço de abertura ao diálogo solidário entre as tradições e culturas diversas.

Para a hermenêutica gadameriana a consciência de pertença é tomada como consciência da diferença por "ter um sentido histórico" (GADAMER, 1998, p, 42), podendo ser vista como uma co-extensão da vida que se tem na contemporaneidade. Deste modo, pode-se argumentar que a herança da Europa, segundo Gadamer, está no âmbito do aprendizado histórico feitos pelos europeus no que se refere ao sentido de se viver com outros, na disposição à prática do que pode ser denominada como uma verdadeira solidariedade, pois nela "nos encontramos como seres humanos" (GADAMER, 1990, p. 116) e assim podemos melhor lidar com os diferentes povos e culturas. Quanto a esta verdadeira solidariedade a que Gadamer se refere, se daria através do comprometimento dos indivíduos em uma convivência social na qual se exige de todas as pessoas a boa vontade que possa ser adquirida e, como também argumenta Axel Honneth "cada um é igual ao outro

\footnotetext{
${ }^{1}$ Ao defender este "outro" que surge ao "meu eu" Gadamer observa que cada indivíduo tem em si a historicidade, que não pode ser negada por ninguém, uma vez que esta tem "vínculo vital que liga a tradição e a origem com a investigação histórica crítica. Mesmo quem procura apagar a sua própria individualidade [...] permanece sempre como um filho de seu tempo e um cidadão da sua pátria". (GADAMER, 2002, p.31).
} 
justamente aí, onde está oposto a ele" (HONNETH, 2009, p. 77). Neste sentido, relacionando estes pensadores, pode-se afirmar que para Gadamer, aqui se irrompe uma nova forma de compreender a realidade histórica, uma vez que a questão da alteridade se mostra de modo central nesta forma de interpretar os fenômenos.

Gadamer defende o diálogo aberto como uma "tolerância" que tem a capacidade de possibilitar o reconhecimento recíproco dos interlocutores no que concerne a conduzir às pretensões de validade, de maneira a permitir o autorreconhecimento e até mesmo a construção do tu, ou seja, da própria identidade dos indivíduos enquanto cidadãos que se reconhecem na alteridade de iguais direitos.

\section{O Projeto Hermenêutico de Gadamer numa Perspectiva Cosmopolita frente ao Pluralismo Cultural}

Ao referir-se à tarefa da hermenêutica filosófica, Gadamer menciona a existência de um desafio quanto à superação de aspectos que possam dificultar o diálogo ou a autocompreensão, parecendo ser este um dos maiores desafios do homem contemporâneo em sua vida comum, ou seja, a própria compreensão de si. Deste modo, como argumenta Gadamer, "assim se coloca com crescente urgência a tarefa de conduzir o homem novamente à autocompreensão de si mesmo. Para isto serve, desde a Antiguidade a filosofia, também sob a forma do que eu chamo de hermenêutica como teoria e também como práxis da arte de compreender e fazer falar o estranho e o que se fez estranho" (GADAMER, 1983, p. 87).

Como defende Gadamer, é preciso que através da filosofia se tenha esta superação das distâncias de modo que aproxime aquilo que é estranho, ou tomado como estrangeiro ou mesmo desconhecido. Este pode ser apresentado através de um texto do passado, obra de arte, língua estrangeira, ou mesmo uma descoberta científica, bem como uma pessoa ou uma cultura que seja distante, sendo "ainda necessário que eu esteja disposto a reconhecer que o outro (ser humano ou não) tem razão e a consentir que ele prevaleça sobre mim" (GADAMER, 1998, p. 14).

Cabe ressaltar que na contemporaneidade vive-se uma ampla autoalienação em relação à própria civilização, uma vez que cada vez mais se vê a dependência da humanidade no que se refere ao que construímos à nossa volta. É, então, neste sentido que se nota a urgência de se conduzir o homem novamente à própria compreensão de si mesmo. Assim, por um lado é notória a ameaça de que, através de um "mundo tecnificado, fiquemos inteiramente submissos ao controle ou mesmo ao domínio de especialistas" (GADAMER, 2001, p.79), por outro, a iminência do risco de que as relações entre a diversidade de culturas sejam cada vez mais conflituosas, podendo alcançar o patamar de dificuldades quando à articulação política dessas sociedades, bem como a convivência em paz no que concerne à dimensão das relações internacionais. Isto remonta à preocupação notada a partir dos últimos textos de Gadamer, onde ele se mostra inquieto quanto ao problema relacionado ao diálogo cultural, uma vez que esta relação entre culturas diferentes proporciona o risco de autodestruição humanitária, pois apenas uma filosofia entendida como arte, cultura, diálogo, é a forma na qual a racionalidade reconhece 0 próprio limite, próprias pretensões e se põe em escuta do outro. No que concerne à dimensão do reconhecimento, como afirma Honneth, 
[...] a categoria de 'reconhecimento mútuo foi para Hegel desde o princípio uma chave para sua ideia de liberdade. Apesar de sua liberdade reflexiva, o homem como sujeito isolado, fica sem comunicação com o mundo externo das entidades e instituições sociais; por mais que busque limitar-se em sua ação somente a objetivos estabelecidos por si mesmo, a realização dos mesmos se torna incerta na realidade objetiva. $O$ anseio da liberdade deixa de constituir um elemento da experiência puramente subjetiva no momento em que o sujeito se encontra com outro sujeito cujos se comportam de maneira com que se complementam os próprios, posto que agora o ego pode ver nas aspirações da outra parte em interação com um componente do mundo externo que permite por em prática objetivamente as metas que o mesmo tenha estabelecido (HONNETH, 2014, p. 67).

Ainda que Gadamer não tenha desenvolvido uma filosofia política, o mesmo acaba sendo referido no que tange à sua contribuição quanto à construção de uma alternativa no que se refere ao diálogo cultural, por "creio que é o pensador mais incisivo sobre a natureza do diálogo dos filósofos do século XX" (BERNSTEIN, 2006, p.159-174). Sempre os textos de Gadamer se referem à dimensão dialógica. Neste sentido, a hermenêutica gadameriana pode ser vista como um esforço para dar voz ao outro, tendo em vista que "toda autocompreensão se realiza ao compreender algo distinto e, inclui a unidade e a mesmidade desse outro" (GADAMER, 2002, p.138). Este "e o estranho tiveram um papel decisivo para a hermenêutica, especialmente por meio das categorias estranheza e familiaridade, constitutivas da compreensão" (HERMANN, 2011, p. 143). Neste sentido, pode-se afirmar que Gadamer se aproxima dos filósofos do diálogo e da alteridade.

Gadamer dá forte ênfase ao encontro de um mundo de sentido estrangeiro, sendo este significado de elevada importância ao mundo com suas diferentes culturas na contemporaneidade, rompendo com uma ideia relativista de incomensurabilidade frente às diferentes visões de mundo e formas de vida. Assim, propõe a linguisticidade como possibilitadora constante de "diálogo crítico" (GADAMER, 2002, p. 223). Este entendido com base na arte de perguntar e estar aberto a perguntas, propiciando "uma atitude crítica frente a todas as convenções" (GADAMER, 2002, p. 199). Para que se possa compreender o geral se faz necessário um modo de ser dialógico, tendo em vista que este amplia a possibilidade de um diálogo que seja exitoso na escuta do outro.

Como afirma Gadamer, "quando vislumbramos algo que nos parecia estranho e incompreensível, quando o alojamos sob nosso mundo ordenado pela linguagem, então, finalmente, a coisa fica clara" (GADAMER, 2002, p. 235). Pelo diálogo se tem esta união da própria autocompreensão e entendimento de formas de vida e visões de mundo que sejam diferentes da própria.

A compreensão hermenêutica de cultura aqui tratada é bem mais ampla que civilização, de modo a fazer remissão à autocompreensão da mesma com valores, crenças e juízos que são compartilhados por uma comunidade. Sua identidade por ser acordada, transformada com uma outra ou até mais culturas que sejam diferentes. Neste sentido cabe a inquietação levantada nesta pesquisa, sobre como a hermenêutica filosófica de Gadamer possibilita à comunidade política ser espaço aberto às diversas culturas em um mundo que constantemente se torna homogeneizador de cidadania. 
Como o próprio Gadamer recomenda, é uma tarefa ética e política a discussão a respeito do encontro de mundos, ou seja, do diálogo entre culturas diferentes. Entretanto, mesmo no outro e no que seja diferente se pode realizar o encontro consigo mesmo. Aqui cabe destacar que Gadamer, em seus últimos escritos dá maior ênfase à hermenêutica tendo como tarefa o escutar a voz do outro, impulsionando à comunidade política ser este encontro de mundos, isto é, aberta ao diálogo de culturas diferentes.

Para buscar resposta ao problema levantado, partimos, então, da própria racionalidade hermenêutica de Gadamer, que é possível pelo encontro com o outro, de modo que neste encontro se nota algo que ainda não havia sido visto. Assim, supera-se uma visão restrita sobre as coisas, abrindo-se um novo horizonte rumo ao que é tomado ainda como desconhecido. O outro pode ser entendido, mais especificamente como algo da tradição - uma obra de arte, um acontecimento que compreendemos de repente - que nos interpela, então, como o interlocutor em um diálogo. Desta maneira, pode-se afirmar que não existem horizontes fechados ou mesmo absolutamente incomensuráveis, conforme se demonstra no processo de fusão de horizontes gadameriano. No diálogo não existe, a princípio, limitações. Pela abertura de horizontes nossas experiências se transformam, particularmente diante do contato com universos culturais diversos. Assim, é "justamente pela via da finitude da particularidade de nosso ser, visível também na diversidade das línguas, se abre o diálogo infinito em direção à verdade que somos" (GADAMER, 2002, p. 223).

Desta maneira é possível afirmar que o Gadamer tardio amplia à hermenêutica filosófica uma tarefa quase política ou cosmo-política em favor do encontro de mundos, ou seja, do diálogo de culturas. A racionalidade dialógica nesta perspectiva do voltar-se ao encontro de mundos é capaz de combater as graves consequências de um mundo em que se tem cada vez mais a autodestruição da própria humanidade, os problemas da crise ecológica, bem como as mais diversificadas formas de intolerâncias dentro das comunidades contemporâneas.

Com isto surge o questionamento a respeito da função da hermenêutica filosófica enquanto prática no âmbito cosmo-político frente ao multiculturalismo. Para isto, Gadamer recorre à dimensão da necessidade da solidariedade, tendo como tarefa não apenas superar a distância e a estranheza do passado, mas também os mesmos dos outros círculos culturais, uma vez que se inserem em uma nova comunidade de vida. Deste modo, encontram novas tarefas rumo à conquista de novos horizontes de sentido. Daí a tarefa urgente em "reconhecer no outro e na alteridade o comum. Em nosso mundo, que está se agrupando de maneira cada vez mais estreita, culturas, religiões, hábitos e avaliações profundamente diversas estão entrando em contato" (GADAMER, 1990, p. 388).

\section{Considerações Finais}

Ao longo desta pesquisa foi possível notar uma elevada contribuição dos filósofos Ricoeur e Gadamer no que tange à discussão a respeito da dimensão ética e política a partir do espectro do outro.

Em Paul Ricoeur podemos concluir que o mesmo em sua problematização da questão do eu chega a fazer uma superação do mesmo, não ficando meramente na discussão do subjetivismo levantado por Descartes na modernidade, onde havia 
uma exaltação do eu - sujeito ao ponto de se fechar apenas no nível da consciência sem dar espaço ao outro.

Ricoeur aponta críticas a Descartes neste sentido, embora lhe dê créditos de elevada colaboração à questão do surgimento do novo paradigma, a saber, a consciência do sujeito. Entretanto, Ricoeur desbrava uma nova alternativa a partir do eu cartesiano e mostra que há espaço para a dimensão da alteridade, tendo em vista que na ipseidade se tem a questão da identidade. Nesta, o si mesmo se encontra com o outro que lhe é próximo, e não estranho, para então desenvolverem o diálogo contínuo nas comunidades ou no que seja tomado como comum.

Para Gadamer, a palavra chave em seu debate filosófico a partir deste texto, é também, a dimensão do outro. Este tomado como aquele que está em constante relação com os demais através do diálogo solidário. Frente a isto, é possível visualizar em seus últimos escritos sua inquietação com os problemas cosmopolíticos, de modo a dar sua colaboração no debate a respeito das culturas diversas, que podem ser entendidas como os outros diante de sua alteridade.

O problema do pluralismo cultural se mostra cada vez mais gerador de conflitos na contemporaneidade, de maneira a causar graves consequências no que se refere aos direitos das minorias que se encontram em situação vulnerável em outras comunidades, nações ou mesmo continentes em que suas culturas originárias são simplesmente desconsideradas, uma vez que estão em 'territórios alheios'.

Neste sentido, Gadamer propõe o diálogo solidário como forma de abertura ao multiculturalismo por parte das sociedades democráticas, de modo a levarem em consideração o aspecto humanitário de cada pequeno grupo que faz parte destas minorias que buscam novas oportunidades de vida em outras sociedades devido às mais diversas situações.

Nota-se, então, que em ambos os autores trabalhados nesta pesquisa existe uma preocupação com a dimensão do outro e suas particularidades, bem como buscam apontar estratégias rumo à compreensão ética a partir do diálogo solidário e compreensivo para que se possa viver em harmonia tomando como comum, a compreensão do outro a partir de si mesmo ao considerar as diferenças existentes em cada caso e circunstância apresentada.

\section{Referências}

BERNSTEIN, Richard J. What is the Difference That Makes a Difference? Gadamer, Habermas, and Rorty. PSA: Proceedings of the Biennial Meeting of the Philosophy of Science Association. Vol. 1982, Volume Two: Symposia and Invited Papers (1982), pp. 331-359. Disponível em: <http://www.jstor.org/stable/192429?seq=1\#page_scan_tab_contents> Acesso em: 25 nov. 2017. 
BERNSTEIN, Richard J. Si la acción fuera o pretendiera ser todo el pensamiento, ese sería el final del pensamento. Richard Bernstein em conversación con la redacción de Areté. Areté Revista de Filosofia, vol. XVIII, № 1 (2006), p. 159-174.

DESCARTES, René. O discurso do método. Rio de Janeiro: José Olímpio, 1960. GADAMER, H. G. La herencia de Europa. Barcelona: Ediciones Península, 1990. La diversidade de las lenguas y la compreensión del mundo: Arte y verdad de la palavra. Barcelona, Paidós, 1998.

Janeiro: Tempo Brasileiro, 1983.

A Razão na Época da Ciência. Trad. de Ângela Dias. Rio de Acotaciones Hermenéuticas. Madrid, Trotta, 2002.

Verdade e Método: traços fundamentais de uma hermenêutica filosófica. Trad. Flávio Paulo Meurer. 10. ed. Petrópolis - Rj: Editora Vozes, 2008.

Verdade e Método II: complementos e índices. Trad. Marcia Sá Cavalcante-Schuback. Petrópolis, RJ: Vozes, 2002.

O Problema da Consciência Histórica. Trad. de Paulo César Duque-Estrada. Rio de Janeiro: Ed. FGV. 1998.

Edições 70, 2001.

Elogia da Teoria. Traduzido por João Tiago Proença. Lisboa:

GRONDIN, Jean. Paul Ricoeur. Tradução de Sybil Safdie Douek. São Paulo: Loyola, 2015.

HERMANN, Nadja. Breve Investigação Genealógica sobre o Outro. Educ. Soc., Campinas, v. 32, n. 114, p. 137 - 149, jan. - mar. 2011. Disponível em <http://www.scielo.br/pdf/es/v32n114/a09v32n114.pdf> Acesso em: 10. nov. 2017.

HONNETH, Axel. Luta por Reconhecimento: a gramática moral dos conflitos sociais. Tradução de Luiz Repa. São Paulo: Editora 34, 2009.

Intelectual, 2014.

El Derecho de la Libertad: una eticidad democrática. Madrid: Clave

LEONHARDT, Ruth Rieth. Pessoalidade e alteridade em Paul Ricoeur. Analecta, v. 5, n. 2, jul/dez. 2004, pp. $43-57$.

PLATÃO. Fédon. Trad. Carlos Garcia Gual. Madrid: Gredos, 1986. v. 3.

RICOEUR, Paul. O si mesmo como outro. Tradução de Ivone C. Benedetti. São Paulo: WMF Martins Fontes, 2014.

SCRUTON, Roger. Introdução à filosofia moderna: de Descartes a Wittgenstein. Rio de Janeiro: Zahar, 1982. 